Research Article

\title{
Prevalence and Associated Factors of Low Birth Weight among Term Newborns in Dilla Town, Southern Ethiopia
}

\author{
Tsegaye Mehare $\mathbb{D}^{1}$ and Yewbmirt Sharew $\mathbb{D}^{2}$ \\ ${ }^{1}$ Depratment of Biomedical Science, College of Medicine and Health Sciences, Dilla University, Dilla, Ethiopia \\ ${ }^{2}$ Depratment of Midwifery, College of Health Sciences, Debre Markos University, Debre Markos, Ethiopia
}

Correspondence should be addressed to Tsegaye Mehare; tseyeshe96@gmail.com

Received 12 February 2020; Revised 9 June 2020; Accepted 29 June 2020; Published 1 August 2020

Academic Editor: Frederick J. Kaskel

Copyright (C) 2020 Tsegaye Mehare and Yewbmirt Sharew. This is an open access article distributed under the Creative Commons Attribution License, which permits unrestricted use, distribution, and reproduction in any medium, provided the original work is properly cited.

\begin{abstract}
Introduction. Birth weight has emerged as the pointer of infant wellbeing and the fundamental focus of infant health policy. Low birth weight predisposes newborns to loads of health disarray like underweight, stunting, hypoglycemia, hypothermia, mental retardation, physical, and neurodevelopment problems which results in high rates of morbidity and mortality. This study aimed to assess the prevalence and associated factors of low birth weights in term newborns. Objective. This study designed to assess the prevalence and associated factors of low birth weight among term newborns in Dilla town, Southern Ethiopia. Materials and Methods. Institutional based cross-sectional study design was used on 472 term newborns. The study setting includes three health centers (Dilla, Wallemi, and Tumetecha) within Dilla town and Dilla University referral hospital from September 1, 2018, to January 30, 2019. The study subjects were mothers with term newborns delivered in the above institutions and those delivered at home and received care within the first 24 hours after delivery in the above health care settings. Results. A total of 161 (34.1\%) of the term newborns were low birth weight. Divorced mothers, rural residents, maternal age $<20$ years old, unwanted and unintended pregnancy, no ANC follow-up, no dietary counsel, no foliate supplementation, and cigarette smoking have shown an association with low birth weight of neonates. Conclusions. Even though the method of sampling used in this study has its confines, the prevalence of low birth weight in this study was higher than the estimate in Ethiopia. Therefore, it is recommended that special attention should be given to pregnant mothers to get adequate rest, additional diet, and antenatal services available and accessible to all pregnant women.
\end{abstract}

\section{Introduction}

Low birth weight (LBW) is defined as having a birth weight of less than 2.5 kilograms irrespective of the gestational age of the neonate according to World Health Organization (WHO) [1]. The chance of the newborn to survive, experience healthy growth, and development was highly determined by birth weight $[2,3]$. Birth weight has emerged as the pointer of infant wellbeing and the fundamental focus of infant health policy [4]. LBW predisposes newborns to many health disarrays like underweight, stunting, hypoglycemia, hypothermia, mental retardation, physical, and neurodevelopment problems which results in high rates of morbidity and mortality $[5,6]$.
Usually, a baby born with less than 2.5 kilograms needs extra hospital care, and there are a regular alarm and uncertainty over future health outcomes [7]. In some developed countries, the proportion of low birth weight ranges from $2-3 \%$ whereas in many developing countries the proportion of LBW range $25-30 \%[8,9]$.

The prevalence of LBW in Ethiopia was 17.3\% [2] which is in line with developing countries $16.5 \%$ [10]. The information on risk factors of LBW was documented at different times and places in Ethiopia. A study on low birth weight among term newborns in Wolieta Sodo health facility showed that the proportion of LBW was $8.1 \%$ [11], a study done in Jimma zone reported 22.5\% LBW [12]. A study in Gondar administrative zone at 12 health institutions in 
1988 reported that the average prevalence of low birth weight was $11.1 \%$ [12]. Another study carried out to determine the prevalence and risk factors for low birth weight in Adwa general hospital revealed that among 424 term newborns 42 (10\%) were LBW [13]; Axum and Laelay Maichew districts reported a LBW rate of $9.9 \%$ and $6.3 \%$, respectively [14].

A study was done in Olkalou district hospital, Kenya, on factors associated with low birth weight among neonates reported that the proportion of LBW was $12.3 \%$ [15]. Moreover, the report from the study on the prevalence of low birth weight and its association with maternal body weight status from 2010 to 2011 in Uganda was (10\%) a bit lower compared to Ethiopia [16]. Nevertheless, the proportion of skilled childbirth attendance is increasing in Ethiopia; we lack adequate evidence on maternal factors which would potentially predict birth outcomes of the newborns in the Dilla area which is characterized by diverse culture and dietary practices. Gedeo zone is one of the most densely populated areas in Ethiopia [17]. Even though, the area is evergreen throughout the year most of the households often suffer from chronic food insecurity even at times of crop harvest $[18,19]$. The evidence on child health and nutritional status predictors particularly attached to maternal health during pregnancy and childbirth was very limited. Thus, the main aim of this study was to determine the prevalence and associated factors of LBW among term newborns in Dilla town, Gedeo zone, South Ethiopia.

\section{Materials and Methods}

2.1. Study Setting. The study was conducted in Dilla town (in three health centers and one referral hospital) from September 1,2018 , to January 30, 2019. Dilla is the capital city of Gedeo zone, SNNPR, Ethiopia; Dilla is $359 \mathrm{~km}$ and $100 \mathrm{~km}$ away from Addis Ababa and Hawassa, respectively. The town has 8 woredas and bordered by Sidama in the north, Oromiya in the south, east, and west. It is also bounded by the rivers Legedara north and east, Michelle in south and Waleme in the west. The town has a Woinadega type of weather condition with a total of 954,120 populations and has one referral hospital, three health centers owned by the government, and other private clinics.

2.2. Study Design. An institution-based cross-sectional study was conducted.

2.3. Study Population. Term newborn mother pair who delivered in the three health centers, one referral hospital, and those delivered at home but received care in the above health institutions within 24 hours of delivery during the study period were considered.

2.4. Sample Size. A sample size of 472 was calculated with the following assumptions: $8.1 \%$ expected proportion of low birth outcome took from similar Ethiopian study [11], 95\% confidence level at 5\% margin of error, and $10 \%$ none response rate considered. Since the total population $(N)$ is less than 10,000, we made a correction formula and multiply by 4 to maximize the sample size. Then, the sample was proportionally allocated to government health facilities in Dilla town based on the number of previous childbirth attendance. Finally, all eligible postpartum mothers to term newborn pairs were consecutively recruited until subsamples for the facilities and the total sample for the study were achieved.

2.5. Inclusion. Term newborn with mother who delivered in the three health centers, one referral hospital, and those delivered at home but received care in the above health institutions within 24 hours of delivery.

2.6. Exclusion. Twins and neonates delivered from mothers who had known chronic or pregnancy-induced pathologies were excluded from the study.

2.7. Data Collection Procedures. Data were collected by trained midwives using structured interviewer-administered questionnaires from mothers. The weights of newborns were measured using the digital Seca balance scale (Germany) to the nearest $1 \mathrm{~g}$. The scale was adjusted to the zero levels before weighing each newborn. Measurement was taken immediately after birth for those delivered in the health institutions, however, for those delivered at home took within the first 24 hours. The investigator supervised the data collectors randomly while interviewing the mothers and weighing newborn babies.

2.8. Data Quality Management. To guarantee the validity of the information gathered, midwives who are well experienced in delivery care were recruited and training was given on techniques of data collection before the actual data collection. The questionnaire was pretested on subjects with the same socio-demographic characteristics in another similar health institution before being applied to the study population, and the necessary modifications were made before the main study. The investigators reviewed and checked the data each day after data collection for its completeness and accuracy.

2.9. Ethics Approval and Consent to Participate. Ethical clearance was obtained from the Institutional Review Committee of Dilla University, College of Medicine and Health Sciences. Official letter of cooperation will be distributed to each of the data collection sites. Before the questionnaire, the aims and objectives of the study were clearly explained to the participants. Verbal informed consent was obtained from each study participant before data collection. Confidentiality of the data was maintained by excluding their identifiers. All participants were involved in this study only with their willingness.

2.10. Statistical Analysis. The entire data collected using a structured questionnaire were validated, edited, coded, and entered into SPSS version 23. Followed by checking for any inconsistencies, descriptive analysis was performed. Descriptive statistics, such as frequencies, and percentages were used to describe the maternal socio-demographic and obstetric history, sex, and weight of the neonates. A chi-square test was used to find the potential association of dependent and independent variables. Bivariate logistic regression analysis was done to decide whether there is an association between 
low birth weight and different factors to select nominee variables for multivariate logistic regression. Variables with $p$ values of up to 0.20 in the bivariate logistic regression analysis were identified and fitted to the multiple logistic regression analysis to identify the independent effects of each variable to the outcome variable. The odds ratio with $95 \%$ confidence intervals (CI) was calculated to distinguish the occurrence and strength of associations, and statistical significance was affirmed if $p<0.05$.

\section{Results}

Socio-demographic characteristics: in this study, a total of 472 singleton deliveries from the three health centers and one referral hospital were included giving a response rate of $100 \%$. The socio-demographic characteristics of mothers studied revealed that $143(30.3 \%)$ were $20-30$ years, 120 (25.4\%) were between 31 and 40 years of age, 108 (22.9\%) were less than 20 years of age, while the remaining 101 (21.4\%) were above 40 years of age. The predominant religion of the study population was found to be Protestant 244 (51.7), followed by Orthodox 98 (20.8\%), and Muslim 75 (15.9\%), while the rest were neither Christians nor Muslims. The predominant ethnic group was 288 (61\%) Gedeo followed by Gurage 73 (15.5\%). Analysis of educational levels of mothers showed that the majority 257 (54.4\%) had elementary education, 111 (23.5\%) had no formal education, while the rest 104 (22\%) had secondary school and above levels of educational. Concerning monthly family income among the study population, $242(51.3 \%)$ earned less than $2001 \mathrm{ETB}$, followed by 119 (25.2\%) who earned between 2001 and $4000 \mathrm{ETB}$, while the rest 111 (23.5\%) earned greater than 4000 ETB. The mothers' response to their occupational status revealed that $107(22.7 \%)$ were farmers, $105(22.2 \%)$ were government employees, 99 (21\%) were merchants, 84 (17.8\%) were daily workers, while the remaining 77 (16.3\%) were housewives. Among the mothers studied, majority 221 $(46.8 \%)$ were married, $130(27.5 \%)$ were unmarried, and the rest $121(25.6 \%)$ were divorced. The majority of the respondents, $369(78.2 \%)$, were urban, and $103(21.8 \%)$ were rural residents (Table 1).

3.1. Maternal Obstetric and Health Service Utilization. Two hundred twenty-three (47.2\%) of mothers were primiparous, $128(27.1 \%)$ of mothers gave 2-4 births, and the rest gave 5 and more births. Concerning pregnancy type among the study population, $173(36.7 \%)$ were wanted but unintended, followed by $168(35.6 \%)$ who were unwanted and unintended, and the rest $131(27.8 \%)$ were wanted and intended. The majority, 235 (49.8\%), of the mothers gave birth to the current newborn with less than two years ( $<24$ months) after previous childbirth. The majority, 225 (47.7\%), had no antenatal care (ANC) follow-up, 124 (26.3\%) had complete follow-up, and the rest of 123 (26.1\%) had 1-3 ANC follow-up during recent pregnancy. 307 (65\%) mothers drank alcohol during pregnancy, and the rest $165(35 \%)$ had not drunk alcohol during pregnancy. 337 (71.4\%) mothers had no cigarette smoking habits during recent pregnancy, whereas 135 (28.6\%) had a cigarette smoking experience. 369 (78.2\%)
TABLE 1: Sociodemographic characteristics of the mothers.

\begin{tabular}{|c|c|c|}
\hline Characteristics & Frequency & Percent \\
\hline \multicolumn{3}{|l|}{ Age category in (years) } \\
\hline$<20 \mathrm{yrs}$ & 108 & 22.9 \\
\hline $20-30 \mathrm{yrs}$ & 143 & 30.3 \\
\hline $31-40 \mathrm{yrs}$ & 120 & 25.4 \\
\hline$>40 \mathrm{yrs}$ & 101 & 21.4 \\
\hline \multicolumn{3}{|l|}{ Residency } \\
\hline Urban & 369 & 78.2 \\
\hline Rural & 103 & 21.8 \\
\hline \multicolumn{3}{|l|}{ Marital status } \\
\hline Married & 221 & 46.8 \\
\hline Divorced & 121 & 25.6 \\
\hline Unmarried & 130 & 27.6 \\
\hline \multicolumn{3}{|l|}{ Level of education } \\
\hline No formal education & 111 & 23.5 \\
\hline Primary education & 147 & 31.2 \\
\hline Grade $7-8$ education & 110 & 23.3 \\
\hline Secondary and above education & 104 & 22.0 \\
\hline \multicolumn{3}{|l|}{ Occupation } \\
\hline Employ & 105 & 22.2 \\
\hline Merchant & 99 & 21.0 \\
\hline Farmer & 107 & 22.7 \\
\hline Housewife & 77 & 16.3 \\
\hline Daily worker & 84 & 17.8 \\
\hline \multicolumn{3}{|l|}{ Monthly income (in birr) } \\
\hline$<1000$ ETB & 101 & 21.4 \\
\hline $1000-2000$ ETB & 141 & 29.9 \\
\hline 2001-4000 ЕТВ & 119 & 25.2 \\
\hline$>4001 \mathrm{ETB}$ & 111 & 23.5 \\
\hline \multicolumn{3}{|l|}{ Ethnicity } \\
\hline Gedeo & 288 & 61.0 \\
\hline Amhara & 29 & 6.1 \\
\hline Oromo & 72 & 15.3 \\
\hline Gurage & 73 & 15.5 \\
\hline Others & 10 & 2.1 \\
\hline \multicolumn{3}{|l|}{ Religion } \\
\hline Protestant & 244 & 51.7 \\
\hline Orthodox & 98 & 20.8 \\
\hline Muslim & 75 & 15.9 \\
\hline Others & 55 & 11.7 \\
\hline
\end{tabular}

mothers affirmed for getting dietary advice during ANC follow-up. The majority of the respondents, 345 (73.1\%), took iron-folic acid. Analysis of sex of neonates showed that slightly more than half, $240(50.8 \%)$, were female, while the rest $232(49.2 \%)$ were male (Table 2$)$.

3.2. Prevalence and Associated Factors of Low Birth Weight $(L B W)$. In this study, $34.1 \%$ of term neonates were found to be LBW. The bivariate logistic regression analysis showed that maternal age, residency, educational status, occupation, 
TABLE 2: Obstetric, nutrition-related characteristics of mothers and sex of neonates.

\begin{tabular}{|c|c|c|}
\hline Characteristics & Frequency & Percent \\
\hline \multicolumn{3}{|l|}{ Parity } \\
\hline Po & 223 & 47.2 \\
\hline 2-4 births & 128 & 27.1 \\
\hline$\geq 5$ births & 121 & 25.6 \\
\hline \multicolumn{3}{|l|}{ Birth interval } \\
\hline$<2$ yrs & 235 & 49.8 \\
\hline $2-3$ yrs & 109 & 23.1 \\
\hline$\geq 4 \mathrm{yrs}$ & 128 & 27.1 \\
\hline \multicolumn{3}{|l|}{ Sex of neonate } \\
\hline Female & 240 & 50.8 \\
\hline Male & 232 & 49.2 \\
\hline \multicolumn{3}{|l|}{ Type of pregnancy } \\
\hline Unwanted and unintended & 168 & 35.6 \\
\hline Wanted but unintended & 173 & 36.7 \\
\hline Wanted and intended & 131 & 27.8 \\
\hline \multicolumn{3}{|l|}{ ANC follow-up } \\
\hline No follow-up & 225 & 47.7 \\
\hline 1-3 follow-up & 123 & 26.1 \\
\hline$\geq 4$ follow-up & 124 & 26.3 \\
\hline \multicolumn{3}{|l|}{ Dietary counsel } \\
\hline Yes & 369 & 78.2 \\
\hline No & 103 & 21.8 \\
\hline \multicolumn{3}{|l|}{ Foliate supplementation } \\
\hline Yes & 345 & 73.1 \\
\hline No & 127 & 26.9 \\
\hline \multicolumn{3}{|l|}{ Alcohol drink at pregnancy } \\
\hline No & 307 & 65.0 \\
\hline Yes & 165 & 35.0 \\
\hline \multicolumn{3}{|l|}{ Smoking status } \\
\hline No & 337 & 71.4 \\
\hline Yes & 135 & 28.6 \\
\hline
\end{tabular}

marital status, birth interval, pregnancy type, ANC followup, dietary counsel, foliate supplementation, alcohol drinking, and cigarette smoking were associated with a low birth weight of neonates. After adjustments for possible effects of confounding variables, ANC follow-up, residency, dietary counsel, foliate supplementation, cigarette smoking, pregnancy type, marital status, and maternal age were significantly and assertively associated with low birth weight.

No ANC follow-up during pregnancy showed a significant association with low birth weight. In epidemiological explanation, this showed us that mothers who had no ANC follow-up were 6.83 times more likely to give low birth weight term neonates as compared to those mothers who had complete ANC follow-up during pregnancy with (AOR: 6.83 95\% CI 3.57, 13.05). Being a rural resident was strongly associated with low birth weight. Those mothers who were rural residents were 6.78 times more likely to give term low birth weight neonates as compared to their counter- parts with (AOR: $6.7895 \%$ CI 3.51, 13.08). The likelihood of delivering low birth weight neonates among mothers who did not get dietary counsel was 6.21 times (AOR: 6.21 95\% CI $3.21,12.02$ ) more compared with mothers who got dietary counsel. Those mothers who did not take folate supplementation during pregnancy were 5.48 times (AOR: 5.48 95\% CI $2.93,10.25$ ) as likely to give term low birth weight neonate as those mothers who took foliate. Furthermore, cigarette smoking during pregnancy was a significant factor associated with low birth weight neonates. Mothers who smoke a cigarette during pregnancy were 4.35 times more likely to give term low birth weight neonate as compared with those mothers who did not smoke with (AOR: 4.35 95\% CI 2.46, 7.69). Unwanted and unintended pregnancy was strongly associated with low birth weight. Those mothers who got pregnant unwanted and unintendedly were 3 times more likely to give term low birth weight neonates compared to mothers who got pregnant in a wanted and intendedly with (AOR: 3.03 95\% CI 1.64, 5.58). Being divorced and age $<20$ years old mothers were another significant factor associated with low birth weight. Divorced as well as age $<20$ years old mothers were 3.12 and 4 times more likely to give term low birth weight neonates as compared to married and age $\geq 40$ years old mothers, respectively, for being divorced (AOR: 2.57 95\% CI 1.43,4.61) and age <20 years old (AOR: 2.46 95\% CI 1.21, 5.00) (Table 3).

\section{Discussion}

The prevalence of LBW in this study was $34.1 \%$, relatively higher than the estimate of LBW from the Ethiopian Demographic Health Survey (EDHS) 2011 (28\%) [20] and Endalamaw et al. [2]. It was also higher than studies conducted on birth weight in Wolaita Sodo and Adwa general hospital in which the prevalence of LBW was found to be $8.1 \%$ in Woliata Sodo [11] and 10\% in Adwa general hospital [13]. Another study undertaken in Jimma Zone on 645 births reported the prevalence rate of LBW (22.5\%) [12]. In 2018, the pooled prevalence of LBW in Ethiopia was reported to be $17.3 \%$ [2], while a study was undertaken to find out the prevalence and factors associated with low birth weight delivery in Axum and Laelay Maichew districts revealed that among the 520 live births $9.9 \%$ were LBW babies [14]. The possible rationalization of high prevalence in the current research could be the internal displacements due to ethnic clash occurred in the border between the Gedeo zone and the Guji zone for the last two years. The other possible justification for differences might be due to poor health education provided by health extension workers to the study participants in the current study area. Also, the current result is higher compared with LBW prevalence (22.30\%) reported from Tanzania during the year 1976-1977 [21].

In this study, the risk of delivering LBW term newborn was found to be significantly higher in those mothers who were residing in rural areas than those residing in urban areas. This may be related to the lifestyles of rural dwellers such as poor balanced diet habits and drinking local alcohol, which is commonly practiced by young women of rural areas. Another possible explanation for the difference might be the 
TABLE 3: Bivariate and multivariate logistic regression analysis of factors associated with low birth weight neonates, Dilla town, Southern Ethiopia.

\begin{tabular}{|c|c|c|c|c|}
\hline \multirow{2}{*}{ Variables } & \multicolumn{2}{|c|}{ LBW } & \multirow{2}{*}{ COR (95\% CI) } & \multirow{2}{*}{$\operatorname{AOR}(95 \% \mathrm{CI})$} \\
\hline & Yes & No & & \\
\hline \multicolumn{5}{|l|}{ Maternal age } \\
\hline$<20$ yrs & $56(51.9 \%)$ & $52(48.1 \%)$ & $2.81(1.58,4.99)$ & $2.46(1.21,500) *$ \\
\hline $20-30 \mathrm{yrs}$ & $42(29.4 \%)$ & $101(70.6 \%)$ & $1.08(0.61,1.91)$ & $1.1(0.56,2.17)$ \\
\hline $31-40 \mathrm{yrs}$ & $35(29.2 \%)$ & $85(70.8 \%)$ & $1.07(0.59,1.93)$ & $0.88(0.43,1.78)$ \\
\hline$\geq 41 \mathrm{yrs}$ & $28((27.7 \%)$ & $73(72.3 \%)$ & Ref & Ref \\
\hline \multicolumn{5}{|l|}{ Level of education } \\
\hline No formal education & $58(52.3 \%)$ & $53(47.7 \%)$ & $2.83(1.60,4.99)$ & $2.21(0.09,52.07)$ \\
\hline Primary education & $42(28.6 \%)$ & $105(71.4 \%)$ & $1.03(0.59,1.81)$ & $0.93(0.04,24.82)$ \\
\hline Grade 7-8 education & $32(29.1 \%)$ & 78 (70.9\%) & $1.06(0.59,1.92$ & $2.39(0.06,90.08)$ \\
\hline$\geq$ secondary education & $29(27.9 \%)$ & $75(72.1 \%)$ & Ref & Ref \\
\hline \multicolumn{5}{|l|}{ Residency } \\
\hline Urban & $114(30.9 \%)$ & $255(69.1 \%)$ & Ref & Ref \\
\hline Rural & $47(45.6 \%)$ & $56(54.4 \%)$ & $1.88(1.20,2.93)$ & $6.78(3.51,13.08) * * *$ \\
\hline \multicolumn{5}{|l|}{ Occupation } \\
\hline Employ & $39(37.1 \%)$ & $66(62.9 \%)$ & Ref & Ref \\
\hline Merchant & $27(27.3 \%)$ & $72(72.7 \%)$ & $0.64(0.35,1.15)$ & $0.68(0.32,1.44)$ \\
\hline Farmer & $29(27.1 \%)$ & $78(72.9 \%)$ & $0.63(0.35,1.13)$ & $0.59(0.28,1.25)$ \\
\hline Housewife & $27(35.1 \%)$ & $50(64.9 \%)$ & $0.91(0.49,1.69)$ & $0.73(0.33,1.64)$ \\
\hline Daily worker & $39(46.4 \%)$ & $45(53.6 \%)$ & $1.47(0.82,2.63)$ & $1.43(0.66,3.11)$ \\
\hline \multicolumn{5}{|l|}{ Marital status } \\
\hline Divorced & $88(39.8 \%)$ & $133(60.2 \%)$ & $1.87(1.16,3.00)$ & $2.57(1.43,4.61) * *$ \\
\hline Never married & $39(32.2 \%)$ & $82(67.8 \%)$ & $1.34(0.78,2.34)$ & $1.56(0.80,3.06)$ \\
\hline Married & $34(26.2 \%)$ & $96(73.8 \%)$ & Ref & Ref \\
\hline \multicolumn{5}{|l|}{ Pregnancy type } \\
\hline Unwanted and unintended & $77(45.8 \%)$ & $91(54.2 \%)$ & $2.51(1.53,4.13)$ & $3.03(1.64,5.58) * * *$ \\
\hline Wanted but unintended & $51(29.5 \%)$ & $122(70.5 \%)$ & $1.24(0.74,2.07)$ & $1.26(0.68,2.34)$ \\
\hline Wanted and intended & $33(25.2 \%)$ & $98(74.8 \%)$ & Ref & Ref \\
\hline \multicolumn{5}{|l|}{ Birth interval } \\
\hline$<2 \mathrm{yrs}$ & $119(50.6 \%)$ & $116(49.4 \%)$ & $5.89(3.39,10.20)$ & $3.05(0.0 .59,15.8)$ \\
\hline $2-3$ yrs & $23(21.1 \%)$ & $86(78.9 \%)$ & $1.53(0.79,2.99)$ & $4.03(0.80,20.37)$ \\
\hline$\geq 4 \mathrm{yrs}$ & $19(14.8 \%)$ & $109(85.2 \%)$ & Ref & Ref \\
\hline \multicolumn{5}{|l|}{ ANC follow up } \\
\hline No follow-up & $117(52 \%)$ & $108(48 \%)$ & $5.31(3.11,9.09)$ & $6.83(3.57,13.05) * * *$ \\
\hline 1-3 follow-up & $23(18.7 \%)$ & $100(81.3 \%)$ & $1.13(0.59,2.17)$ & $1.04(0.49,2.20)$ \\
\hline$\geq 4$ follow up & $21(16.9 \%)$ & $103(83.1 \%)$ & Ref & Ref \\
\hline \multicolumn{5}{|l|}{ Dietary counsel } \\
\hline Yes & $113(30.6 \%)$ & $256(69.4 \%)$ & Ref & Ref \\
\hline No & $48(46.6 \%)$ & $55(53.4 \%)$ & $1.98(1.27,3.09)$ & $6.21(3.21,12.02) * * *$ \\
\hline \multicolumn{5}{|l|}{ Foliate supplementation } \\
\hline Yes & $100(29 \%)$ & $245(71 \%)$ & Ref & Ref \\
\hline No & $61(48 \%)$ & $66(52 \%)$ & $2.26(1.49,3.44)$ & $5.48(2.93,10.25) * * *$ \\
\hline \multicolumn{5}{|l|}{ Alcohol drink } \\
\hline No & $86(28 \%)$ & $221(72 \%)$ & Ref & Ref \\
\hline Yes & $75(45.5 \%)$ & $90(54.5 \%)$ & $2.14(1.44,3.18)$ & $1.91(0.78,4.66)$ \\
\hline
\end{tabular}


TABLE 3: Continued.

\begin{tabular}{|c|c|c|c|c|}
\hline \multirow{2}{*}{ Variables } & \multicolumn{2}{|c|}{ LBW } & \multirow{2}{*}{ COR $(95 \% \mathrm{CI})$} & \multirow{2}{*}{ AOR (95\% CI) } \\
\hline & Yes & No & & \\
\hline \multicolumn{5}{|c|}{ Cigarette smoking } \\
\hline No & $99(29.4 \%)$ & $238(70.6 \%)$ & Ref & Ref \\
\hline Yes & $62(45.9 \%)$ & $73(54.1 \%)$ & $2.04(1.35,3.08)$ & $4.35(2.46,7.69) * * *$ \\
\hline
\end{tabular}

study settings, such as access to the health facility and acquiring maternal care education through media is more common in urban than rural. Maternal age was an important determinant of the low birth weight of term neonates in this study. Mothers who had less than 20 years at the time of delivery gave a higher proportion of LBW babies as compared to mothers whose age were greater than or equal to 40 years old. This result is similar to the study conducted in Adwa [13], systematic review, and meta-analysis in Ethiopia [2], Nepal [22], and India [23]. In this study, marital status enlightened a significant association with low birth weight. Divorced mothers had higher odds to delivered term LBW neonates than mothers who were married.

The pregnancy type was also another associated factor for the term LBW. Those mothers whose pregnancies were unwanted and unintended gave more low birth weight neonate as compared to those mothers whose pregnancies were wanted as well as intended. This finding is in line with studies carried out on low birth weight and associated factors in Axum and Laelay Maichew districts [14], Adwa general hospital [13]. This might be explained by the fact that mothers might not be ready psychologically, economically, and nutritionally; therefore, they did not take extra diet during the entire pregnancy period. Similarly, those mothers who did not take folate supplementation during pregnancy were more likely to give term LBW neonates as compared to those mothers who took foliate. The protective function of foliate supplementation to the low birth weight of neonate is supported by the previous study conducted in Adwa general hospital [13], Nepal [22], and America [24]. The physiological mechanism of iron supplementation on birth weight is not understood; however, there are two hypotheses about improvements in birth weight due to iron supplements [24]. First, iron supplementation helps to improve appetite which improves the overall nutritional status of mothers. Second, iron deficiency anemia leads to change in norepinephrine, cortisol, and corticotrophin that result in oxidative stress to fetal growth which is reduced by iron supplementation $[24,25]$.

Furthermore, in this study, we observed that those mothers who had not ANC follow-up and dietary counsel were more likely to give term LBW neonates as compared to mothers who had complete ANC follow-up and dietary counsel, respectively. The current findings are supported by findings from 2006 to 2011 NDHS [22], Axum and Laelay Maichew districts [14], Jimma [12], and Gondar [26]. The possible explanation could be ANC visits are likely to influence improvements in dietary practices, monitor and encour- age recommended weight gain during pregnancy, and improve neonatal outcomes.

Lastly, smoking was another maternal factor significantly associated with the term LBW. Mothers who had a habit of smoking during pregnancy were more likely to give LBW neonates as compared with nonsmoker mothers. There was a dissimilar result done by Cogswell et al. [24].

\section{Conclusion and Recommendation}

The magnitude of low birth weight in Dilla town was too high. ANC follow-up, residency, dietary counsel, foliate supplementation, cigarette smoking, pregnancy type, marital status, and maternal age showed significant association with LBW neonates. Thus, it is recommended that special attention should be given to pregnant mothers to get adequate rest and additional diet, and making antenatal services available and accessible timely to all pregnant women is recommended to minimize the prevalence of low birth weight.

\section{Abbreviations \\ LBW: Low birth weight \\ AOR: Adjusted odds ratio \\ CI: $\quad$ Confidence interval \\ SPSS: $\quad$ Statistical package for social science \\ ANC: Antenatal care \\ SNNPR: South Nation Nationalities and People's Region \\ WHO: World Health Organization.}

\section{Data Availability}

The datasets analyzed during the current study are available from the corresponding author on reasonable request.

\section{Conflicts of Interest}

The authors report no conflicts of interest in this work.

\section{Acknowledgments}

The authors' deep appreciation goes to Dilla University, College of Medicine and Health Sciences, for appropriate review and authorization of this paper. The authors would also like to extend their gratitude to health workers in the data collection sites, data collectors, and supervisors for precious contributions to the success of this study. 


\section{References}

[1] UNICEF-WHO, "Low Birthweight Estimates," Levels and trends 2000-2015, 2015.

[2] A. Endalamaw, E. H. Engeda, D. T. Ekubagewargies, G. M. Belay, and M. A. Tefera, "Low birth weight and its associated factors in Ethiopia: a systematic review and meta-analysis," Italian Journal of Pediatrics, vol. 44, no. 1, p. 141, 2018.

[3] M. Ornstein, A. Ohlsson, J. Edmonds, and E. Asztalos, "Neonatal follow-up of very low Birthweight/Extremely low Birthweight infants to school age: a critical overview," Acta Paediatrica, vol. 80, no. 8-9, pp. 741-748, 1991.

[4] S. Badshah, L. Mason, K. McKelvie, R. Payne, and P. J. Lisboa, "Risk factors for low birthweight in the public-hospitals at Peshawar, NWFP-Pakistan," BMC Public Health, vol. 8, no. 1, p. 197, 2008.

[5] R. Shrimpton, "Preventing low birthweight and reduction of child mortality," Transactions of the Royal Society of Tropical Medicine and Hygiene, vol. 97, no. 1, pp. 39-42, 2003.

[6] M. Hack, N. K. Klein, and H. G. Taylor, "Long-term developmental outcomes of low birth weight infants," The Future of Children, vol. 5, no. 1, pp. 176-196, 1995.

[7] WHO, Guidelines on optimal feeding of low birth weight infants in low and middle-income countries, World Health Organization, Geneva, Switzerland, 2011.

[8] A. K. Blanc and T. Wardlaw, "Monitoring low birth weight: an evaluation of international estimates and an updated estimation procedure," Bulletin of the World Health Organization, vol. 83, pp. 178-185, 2005.

[9] WHO AJ, Technical Report Series, 1976.

[10] P. Bharati, M. Pal, M. Bandyopadhyay, A. Bhakta, and S. Chakraborty, "Prevalence and causes of low birth weight in India," Malaysian Journal of Nutrition, vol. 17, no. 3, 2011.

[11] S. Kastro, T. Demissie, and B. Yohannes, "Low birth weight among term newborns in Wolaita Sodo town, South Ethiopia: a facility-based cross-sectional study," BMC Pregnancy and Childbirth, vol. 18, no. 1, p. 160, 2018.

[12] T. Tema, "Prevalence and determinants of low birth weight in Jimma Zone, Southwest Ethiopia," East African Medical Journal, vol. 83, no. 7, p. 366, 2006.

[13] Y. Gebregzabiherher, A. Haftu, S. Weldemariam, and H. Gebrehiwet, "The Prevalence and Risk Factors for Low Birth Weight among Term Newborns in Adwa General Hospital, Northern Ethiopia," Obstetrics and gynecology international, vol. 2017, 7 pages, 2017.

[14] N. Teklehaimanot, T. Hailu, and H. Assefa, "Prevalence and factors associated with low birth weight in Axum and laelay maichew districts, North Ethiopia: a comparative Cross Sectional study," International Journal of Nutrition and Food Sciences, vol. 3, no. 6, pp. 560-566, 2014.

[15] O. M. Muchemi, E. Echoka, and A. Makokha, "Factors associated with low birth weight among neonates born at Olkalou District Hospital, Central Region, Kenya," Pan African Medical Journal, vol. 20, no. 1, 2015.

[16] Z. He, G. Bishwajit, S. Yaya, Z. Cheng, D. Zou, and Y. Zhou, "Prevalence of low birth weight and its association with maternal body weight status in selected countries in Africa: a crosssectional study," BMJ Open, vol. 8, no. 8, article e020410, 2018.

[17] Y. Mekonnen, "Patterns of maternity care service utilization in Southern Ethiopia: evidence from a community and family survey," Ethiopian Journal of Health Development, vol. 17, no. 1, pp. 27-33, 2003.

[18] B. Lindtjørn, D. Mitiku, Z. Zidda, and Y. Yaya, "Reducing maternal deaths in Ethiopia: results of an intervention Programme in Southwest Ethiopia," PLoS One, vol. 12, no. 1, p. e0169304, 2017.

[19] T. Azeze and B. Haji, “Assessment of knowledge gap and constraints affecting consumption of standardized dairy products in Sidama and Gedeo Zone, Southern Ethiopia," Journal of Scientific and Innovative Research, vol. 6, no. 1, pp. 25-32, 2017.

[20] Agency, "Cs: Ethiopia Demographic and Health Survey," Central Statistical Agency and ORC Macro, 2011.

[21] World Health Organization, "Division of Family Health. The incidence of low birth weight: a critical review of available information," World Health Statistics Quarter Reports, vol. 33, pp. 197-204, 1980.

[22] V. Khanal, Y. Zhao, and K. Sauer, "Role of antenatal care and iron supplementation during pregnancy in preventing low birth weight in Nepal: comparison of national surveys 2006 and 2011," Archives of Public Health, vol. 72, no. 1, p. 4, 2014.

[23] R. D. Potdar, S. A. Sahariah, M. Gandhi et al., "Improving women's diet quality preconceptionally and during gestation: effects on birth weight and prevalence of low birth weight-a randomized controlled efficacy trial in India (Mumbai Maternal Nutrition Project)," The American Journal of Clinical Nutrition, vol. 100, no. 5, pp. 1257-1268, 2014.

[24] M. E. Cogswell, I. Parvanta, L. Ickes, R. Yip, and G. M. Brittenham, "Iron supplementation during pregnancy, anemia, and birth weight: a randomized controlled trial," The American Journal of Clinical Nutrition, vol. 78, no. 4, pp. 773-781, 2003.

[25] L. H. Allen, "Biological mechanisms that might underlie iron's effects on fetal growth and preterm birth," The Journal of Nutrition, vol. 131, no. 2, pp. 581S-589S, 2001.

[26] A. A. Adane, T. A. Ayele, L. G. Ararsa, B. D. Bitew, and B. M. Zeleke, "Adverse birth outcomes among deliveries at Gondar University hospital, Northwest Ethiopia," BMC Pregnancy and Childbirth, vol. 14, no. 1, p. 90, 2014. 